\title{
Peer Coaching to Improve Diabetes Self-Management Among Low-Income Black Veteran Men: A Mixed Methods Assessment of Enrollment and Engagement
}

\author{
Cassie D. Turner, MSW $W^{1,2}$ \\ Rebecca Lindsay, MPH', \\ Michele Heisler, MD, MPA ${ }^{1,2,3}$ \\ 'Department of Internal Medicine, Univer- \\ sity of Michigan, Ann Arbor, Michigan \\ ${ }^{2}$ Center for Clinical Management Research, \\ Ann Arbor Veterans' Affairs (VA) Health- \\ care System, Ann Arbor, Michigan \\ ${ }^{3}$ Department of Health Behavior \\ and Health Education, School of Public \\ Health, University of Michigan, Ann Arbor, \\ Michigan
}

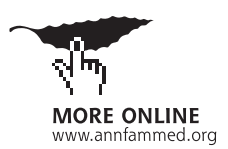

Conflicts of interest: authors report none.

\section{CORRESPONDING AUTHOR}

Cassie D. Turner

University of Michigan 2800 Plymouth Rd, Bldg 16 Ann Arbor, MI 48109-2800 cpringle@med.umich.edu

\begin{abstract}
PURPOSE We undertook a study to ascertain patient characteristics associated with enrollment and engagement in a type 2 diabetes peer health coaching program at an urban health care facility serving predominantly Black veteran men, to improve the targeting of such programs.
\end{abstract}

METHODS A total of 149 patients declined enrollment in a randomized controlled trial but provided sociodemographic, clinical, and psychosocial information. A total of 290 patients enrolled and were randomized to 2 peer coaching programs; they provided sociodemographic, clinical, and survey data, and were analyzed according to their level of program engagement (167 engaged, 123 did not engage) irrespective of randomization group. Qualitative interviews were conducted with 14 engaged participants.

RESULTS Patients who enrolled were more likely to be Black men, have higher levels of education, have higher baseline hemoglobin $A_{1 c}$ levels, describe their diabetes self-management as "fair" or "poor," and agree they "find it easy to get close to others" ( $P<.05$ for each). At the program's end, patients who had engaged were more likely than those who had not to describe their peer coaches as being supportive of their autonomy (mean score, 85.4 vs 70.7; $P<.001$ ). The importance of coaches being encouraging, supportive, and having common ground/shared experiences with participants also emerged as key themes in interviews with engaged participants.

CONCLUSIONS Individuals with greatest perceived need were more likely to enroll in our trial of peer coaching, but the only factor associated with engagement was finding one's coach to support autonomy. Our findings reinforce the importance of training and ensuring fidelity of peer coaches to autonomysupportive communication styles for participant engagement. In tailoring peer support programs for Black men, future research should elucidate which shared characteristics between participant and peer coach are most important for engagement and improved outcomes.

Visual abstract

Ann Fam Med 2021;19:532-539. https://doi.org/10.1370/afm.2742.

\section{INTRODUCTION}

B lack Americans have a significantly higher prevalence of type 2 diabetes when compared with non-Hispanic White Americans. ${ }^{1-3}$ Although many studies have sought to understand and address these disparities, most of that research has been conducted with Black women, leaving a gap in our understanding about how to address type 2 diabetes among Black men. ${ }^{4-6}$ Black men have a higher risk of developing this disease when compared with Black women and non-Hispanic White individuals. ${ }^{3}$ After diagnosis, Black men have a disproportionately greater risk of diabetesrelated complications (such as heart disease, renal failure, and limb amputations), on average have higher hemoglobin $\mathrm{A}_{1 \mathrm{c}}\left(\mathrm{HbA}_{\mathrm{lc}}\right)$ levels, and experience more barriers to diabetes self-management ${ }^{7,8}$ when compared with 
non-Hispanic White individuals. ${ }^{9,10}$ Also, Black men report less participation in health care clinic visits. ${ }^{11-14}$ Relatedly, veterans are disproportionately affected by type 2 diabetes and are 3 times more likely to have diabetes than the general population, with higher prevalence and severity among Black veterans, ${ }^{15,16}$ highlighting the importance of better understanding how to reduce disparities within these populations.

Adults with type 2 diabetes are instructed by their health care professionals to engage in a range of self-management behaviors, but adherence is challenging ${ }^{17,18}$ and disparities exist in self-management among Black men and Black male veterans compared with their White counterparts. ${ }^{14,19}$ Yet, Black men have disproportionately low rates of enrollment in diabetes self-management interventions. ${ }^{20}$ For Black men, gender-based values and beliefs along with strong social support play a critical role in diabetes self-management. ${ }^{20}$ Peer support interventions are one effective way to mobilize social support for diabetes prevention and self-management, ${ }^{21,22}$ are increasingly available in health care and other community settings, ${ }^{23-25}$ and have demonstrated effectiveness in improving diabetes and patient-centered outcomes. ${ }^{26-29}$ Although peer support programs are a promising strategy for addressing health disparities in Black men, ${ }^{30}$ they may be underused, ${ }^{31,32}$ highlighting the importance of understanding the characteristics of those who enroll and engage in these programs. Existing literature shows characteristics of who enrolls in diabetes peer support interventions, but there is a lack of research that examines characteristics of engagement, especially among Black men. ${ }^{33}$ Possible factors contributing to this situation include a lack of Black male representation in samples in research on type 2 diabetes, a decreased likelihood of Black men enrolling, and an increased likelihood of dropping out of disease self-management research. ${ }^{4,20}$

To address this gap in knowledge, we examined characteristics of participants in a peer coaching program evaluated in a randomized controlled trial among veterans with type 2 diabetes and high $\mathrm{HbA}_{1 \mathrm{c}}$ levels at the John D. Dingell Veterans Affairs (VA) Medical Center in Detroit, Michigan. In this study, $60 \%$ of those contacted declined to enroll and nearly one-half of participants who enrolled did not engage in the program as it was designed (ie, minimum engagement of talking with their coach at least twice a month). All program participants had improved $\mathrm{HbA}_{1 \mathrm{c}}$ values at 6 months and maintained their improvements at 12 months. ${ }^{34}$ Those who engaged in the program showed greater improvements in $\mathrm{HbA}_{1 \mathrm{c}}$ values than those who did not. We therefore sought to answer 4 key questions: (1) Who agreed to enroll in the diabetes peer coaching trial? (2) What differences, if any, were there between those who enrolled and those who did not? (3) Who engaged in the intervention (participated in at least 2 telephone calls per month with a peer coach)? and (4) What were key themes and illustrative experiences among those who engaged in the intervention?

\section{METHODS}

\section{Design}

Our trial was approved by the Central Veteran's Administration institutional review board (protocol 13-35). Details of this parallel, 2-arm randomized controlled trial of a 6-month peer coaching program have been described in detail elsewhere. ${ }^{34,35}$ Briefly, patients at the John D. Dingell VA Medical Center in Detroit, MI, were eligible if they had high $\mathrm{HbA}_{1 \mathrm{c}}$ values (ie, at least $8.0 \%$ if aged younger than 70 years and at least $8.5 \%$ if aged 70 years and older). Patients were contacted by letter and called by a research assistant 2 to 6 weeks after an $\mathrm{HbA}_{\mathrm{cc}}$ level in the eligible range was posted in the electronic health record (Figure 1). After a brief screening to ensure the patient received diabetes care at the VA, was not currently enrolled in other diabetes interventions, and was able to participate in intervention activities, the patient was asked to join the study. Patients who declined were asked to answer questions that would help determine whom this kind of peer support program would appeal to. Of patients declining to enroll, $40 \%$ agreed to provide sociodemographic information and complete survey measures on their social support, general health, and diabetes self-management. In addition to completing those measures, enrolled patients also completed additional survey and physical measures at baseline, at the end of the 6-month intervention, and at a 12 -month follow-up.

Enrollment occurred from September 2014 to September 2016. Of 739 patients who were contacted, 290 patients were enrolled over a period of 2 years.

Participants were randomized to 2 peer coaching programs. All enrolled patients were assigned a peer coach who was a fellow patient with diabetes who formerly had consistently high $\mathrm{HbA}_{1 \mathrm{c}}$ values, had achieved improvements in recent months, and had received initial training in motivational interviewing skills and action planning. To the extent possible, patients were matched with a coach of the same sex, race, approximate age $( \pm 7$ years), and insulin use. Both groups had an initial inperson session with their assigned coach in which the peer coach helped the participant identify a behavioral goal related to their diabetes care and specific action steps for the next week to meet that goal (an action plan). The only difference between the 2 groups was that in 1 group, the peer coach used an interactive, personally tailored e-health tool during that initial session. 


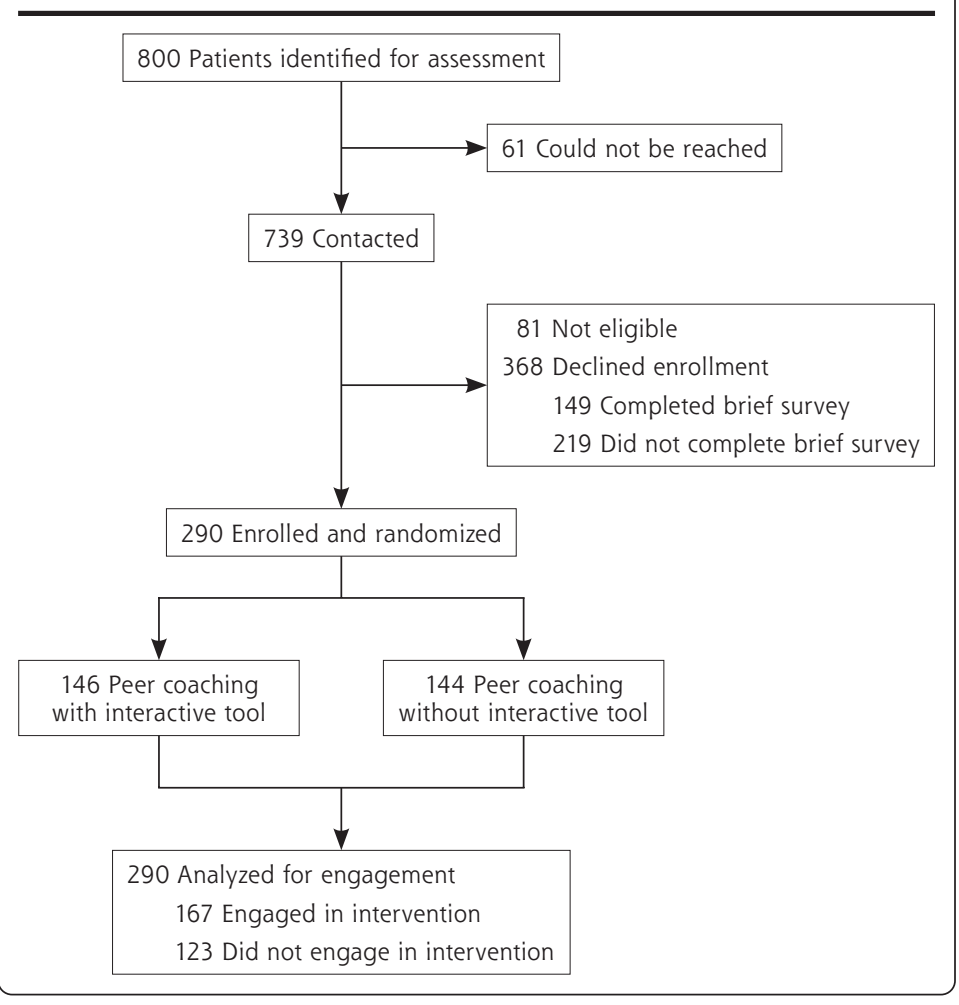

\section{Figure 1. Study flow diagram.}

their coach was of their autonomy using the well-validated Health Care Climate Questionnaire. The questionnaire is a 12 -item scale that assesses patients' perceptions of the degree to which they experience their assigned peer coach to be supportive of autonomy vs controlling in providing general health support or with respect to a specific health care issue. It was originally validated in a study of patients visiting their primary care physicians and has since been used in multiple studies of professional and lay health care supporters. ${ }^{43-45}$ Possible scores range from 1 to 7 , with higher scores representing a higher level of perceived autonomy supportiveness; these scores were also converted to values ranging from 1 to 100 to facilitate comparisons.

\section{Semistructured Interviews}

Toward the end of the 6-month intervention, we conducted semistructured interviews among a purposive sample of participants. In this study, we focused on the interviews with participants who met the criteria for engagement in the Thereafter, all peer coaches were instructed to call their peer partners at least once a week to check in, ask about progress on the action plan, offer encouragement, and, if necessary, help the peer partner brainstorm solutions to barriers in completing action steps. To place calls, coaches dialed a toll-free number connected to an interactive voice response telephone system and followed prompts to connect to their assigned peer partner(s). The interactive voice response system also recorded call date, time, and duration.

\section{Measures}

In addition to providing education, employment, marital status, racial/ethnic background, and annual household income, patients who declined enrollment and all enrolled patients answered pre-enrollment questions. These questions included validated scales for self-reported health status, ${ }^{36}$ diabetes self-management ability, ${ }^{37}$ ease of establishing social relationships, ${ }^{38}$ and satisfaction with their health care. ${ }^{39}$ Patients who enrolled also completed a baseline survey that included measures of medication adherence and exercise ${ }^{40}$ diabetes distress, ${ }^{41}$ and decision conflict. ${ }^{42}$ Possible scores varied across scales and were converted to values ranging from 1 to 100 to facilitate comparisons.

At the conclusion of the 6-month intervention period, enrolled patients evaluated how supportive intervention. Engagement was defined as participation in at least 2 calls per month with a peer coach, as captured by the interactive voice response telephone system. At least 2 team members conducted each of the interviews with 14 engaged participants, 10 of whom were Black men; 9 of those 10 had a peer coach who was also Black. All participants gave informed consent before these interviews, which lasted 45 minutes to an hour and took place at the Detroit VA clinic or via telephone between June 2016 and May 2017. Interviews were audiotaped, reviewed, and transcribed immediately after occurring. Thematic saturation was achieved after interviewing 10 Black male participants, with no additional themes emerging after interviews with 4 White male participants.

\section{Quantitative Analysis}

We compared differences between patients who did and did not enroll and between patients who did and did not engage on all available study variables. We used the Pearson $\chi^{2}$ test for categorical variables and the $t$ test for continuous measures. Stata 13.0 (StataCorp LLC) was used for all analyses.

\section{Qualitative Analyses}

We used a grounded theory approach for each step of the qualitative analysis. ${ }^{46}$ Three research assistants who 
were trained in qualitative interviewing and analysis completed all interviews using the interview guide domains (Supplemental Appendix, available at https:// www.AnnFamMed.org/lookup/ suppl/doi:10.1370/afm.2742/-/DC1). Each transcript was reviewed for clarity, content, and emerging themes, which were drafted into a codebook. Team members then independently coded transcripts and team discussions, resolved coding inconsistencies, added or removed codes, and further defined codes until agreement was reached. After the codebook was finalized, 2 research assistants individually coded each transcript. Coding discrepancies were discussed with a third research assistant until consensus was reached and this process continued until concordance was reached. The final coded transcripts were analyzed with NVivo software (QSR International).

\section{RESULTS}

As shown in Figure 1, the rate of trial enrollment was $44 \%$ (290 of 658 eligible patients). Of those who declined to enroll, 40\% (149 of 368) completed the screening questions. Of those who enrolled, $58 \%$ (167 of 290) met our established a priori criterion for engagement in the intervention.

Characteristics of those who enrolled in the study and those who declined but completed the brief survey are shown in Table

1. Those who enrolled were significantly more likely to be Black, to have more than a high school education, to have higher baseline $\mathrm{HbA}_{1 \mathrm{c}}$ values, and to rate their own diabetes self-management as "fair" or "poor" ( $P<.05$ for each). They also were significantly more likely to report that they "found it easy to get close to other people" $(P<.001)$.

Among enrolled participants, there were no significant differences in baseline characteristics between those who did and did not engage (Table 2). At the 6-month follow-up, however, participants who evaluated their peer coaches highly on the validated
Table 1. Pre-Enrollment Characteristics by Enrollment Status

\begin{tabular}{|c|c|c|c|}
\hline Characteristic & $\begin{array}{l}\text { Not Enrolleda } \\
\quad(n=149)\end{array}$ & $\begin{array}{l}\text { Enrolled } \\
(n=290)\end{array}$ & $\begin{array}{c}P \\
\text { Value }\end{array}$ \\
\hline Age, mean (SD), y & $66.9(10.9)$ & $63.7(10.1)$ & .13 \\
\hline Sex: male, No. (\%) & $143(96.0)$ & $283(97.6)$ & .35 \\
\hline Race: Black, No. (\%) & $57(41.6)$ & $170(60.9)$ & $<.001$ \\
\hline Education > high school graduate, No. (\%) & $84(56.8)$ & $200(69.0)$ & .01 \\
\hline $\mathrm{HbA}_{1 \mathrm{c}}$, mean (SD), \% & $9.18(1.37)$ & $9.51(1.54)$ & .03 \\
\hline Employed, No. (\%) & $31(21.4)$ & $74(25.8)$ & .31 \\
\hline Annual income $<\$ 30,000$, No. (\%) & $57(59.4)$ & $142(57.5)$ & .75 \\
\hline Finds it easy to get close to others, No. (\%) & $97(67.4)$ & $237(81.7)$ & $<.001$ \\
\hline Diabetes self-management: fair/poor, No. (\%) & $46(31.5)$ & $145(50.0)$ & $<.001$ \\
\hline Self-reported health status: fair/poor, No. (\%) & $64(43.8)$ & $129(44.5)$ & .90 \\
\hline Satisfied with VA health care, No. (\%) & $140(93.9)$ & $270(93.1)$ & .58 \\
\hline
\end{tabular}

Table 2. Characteristics by Engagement Status

\begin{tabular}{|c|c|c|c|}
\hline Characteristic & $\begin{array}{l}\text { Not Engaged } \\
\quad(n=123)\end{array}$ & $\begin{array}{l}\text { Engaged } \\
(\mathrm{n}=167)\end{array}$ & $\begin{array}{c}P \\
\text { Value }\end{array}$ \\
\hline Age, mean (SD), y & $64.0(10.1)$ & $62.6(10.2)$ & .27 \\
\hline Sex: male, No. (\%) & $122(99.2)$ & $161(96.4)$ & .13 \\
\hline Race: Black, No. (\%) & $73(59.3)$ & $108(65.1)$ & .61 \\
\hline Education > high school graduate, No. (\%) & $36(29.3)$ & $54(32.3)$ & .58 \\
\hline $\mathrm{HbA}_{1 c}$, mean (SD), \% & $9.1(1.7)$ & $9.1(1.7)$ & .94 \\
\hline Employed, No. (\%) & $30(24.6)$ & $44(26.7)$ & .69 \\
\hline Annual income, $<\$ 30,000$, No. (\%) & $60(59.4)$ & $82(56.2)$ & .61 \\
\hline Finds it easy to get close to others, No. (\%) & $85(69.1)$ & $126(75.4)$ & .23 \\
\hline Diabetes self-management: fair/poor, No. (\%) & $54(43.9)$ & $91(54.5)$ & .08 \\
\hline Self-reported health status: fair/poor, No. (\%) & $57(46.3)$ & $72(43.1)$ & .58 \\
\hline Satisfied with VA health care, No. (\%) & $113(91.9)$ & $157(94.0)$ & .20 \\
\hline Type 2 diabetes distress score, mean (SD) ${ }^{a}$ & $71.5(26.0)$ & $74.5(22.1)$ & .31 \\
\hline Medication adherence score, mean (SD) ${ }^{a}$ & $90.9(20.7)$ & $89.6(20.7)$ & .60 \\
\hline Exercise score, mean (SD) ${ }^{a}$ & $43.8(32.4)$ & $40.6(31.6)$ & .41 \\
\hline $\begin{array}{l}\text { Coach autonomy supportiveness scale score, } \\
\text { mean (SD) }\end{array}$ & $70.7(24.7)$ & $85.4(16.0)$ & $<.001$ \\
\hline \multicolumn{4}{|l|}{$\mathrm{HbA}_{\mathrm{lc}}=$ hemoglobin $\mathrm{A}_{\mathrm{lc}} ; \mathrm{VA}=$ Veterans Affairs. } \\
\hline \multicolumn{4}{|c|}{$\begin{array}{l}\text { a Possible values range from } 1 \text { to } 100 \text {, with higher values indicating higher level of distress, greater medi- } \\
\text { cation adherence, higher frequency of exercise, and higher level of perceived autonomy supportiveness, } \\
\text { respectively. }\end{array}$} \\
\hline
\end{tabular}

autonomy supportiveness scale were significantly more likely to have engaged in the intervention than participants who rated their coaches lower on autonomy supportiveness (mean score, 85.4 vs 70.7; $P<.001$ ).

Regardless of engagement status, participants experienced clinically and statistically significant improvements in $\mathrm{HbA}_{1 \mathrm{c}}$ levels when compared with baseline at the end of the intervention and maintained those improvements at the 12-month follow up (Table 3 ). At the end of the intervention, engaged participants achieved improvements that were greater (though not 
Table 3. Effect of Engagement on Change in $\mathrm{HbA}_{1 \mathrm{c}}$ Level From Baseline

\begin{tabular}{|c|c|c|c|c|c|}
\hline \multirow[b]{2}{*}{ Time } & \multicolumn{2}{|c|}{ HbA $_{1 c}$ Level, Mean, \% } & \multicolumn{2}{|c|}{$\mathrm{HbA}_{1 \mathrm{c}}$ Change, ${ }^{\mathrm{a}}$ Mean, \% } & \multirow{2}{*}{$\begin{array}{l}\text { Between-Group Difference } \\
\text { in } \mathrm{HbA}_{1 \mathrm{c}} \text { Change, }{ }^{\mathrm{a}} \text { Coefficient }\end{array}$} \\
\hline & Not Engaged & Engaged & Not Engaged & Engaged & \\
\hline Baseline & 9.07 & 9.08 & $\ldots$ & $\ldots$ & $\ldots$ \\
\hline 6 months & 8.58 & 8.27 & $-0.50(P=.01)$ & $-0.81(P<.001)$ & $0.32(P=.19)$ \\
\hline 12 months & 8.52 & 8.55 & $-0.61(P=.01)$ & $-0.51(P=.001)$ & $0.10(P=.71)$ \\
\hline
\end{tabular}

statistically significantly so because of the small sample size) when compared with those who did not engage.

At the 12-month follow-up, improvements were comparable for the groups.

In the semistructured interviews with engaged participants, several key themes emerged about factors that contributed to their engagement in the intervention. These themes are given in Table 4 along with illustrative quotes from the 10 Black interviewees. The themes were (1) common ground and shared experiences with the coach $_{i}(2)$ encouraging, supportive, and authentic stance from the $\operatorname{coach}_{i}(3)$ accountability and consistency from the $\operatorname{coach}_{i}(4)$ receiving helpful tips and self-management information from the coach; and (5) having an intentional focus on improving self-management behaviors.

In general, comments during the interviews demonstrated that these themes and experiences were interconnected and instrumental in their adoption and maintenance of self-management strategies. Participants repeatedly emphasized the helpfulness of having a fellow male veteran to talk with on a consistent basis about their challenges with diabetes and self-management. Also, they commonly endorsed how helpful it was to have someone who had similar experiences to provide useful tips and information, but in a way that balanced providing accountability with being supportive and encouraging.

\section{DISCUSSION}

Specifically for Black men, numerous studies have noted sociocultural factors that contribute to lack of participation in health research and diabetes self-management programs. These factors include medical mistrust, perceived racism in health care, and gender values and beliefs. ${ }^{20,47,48}$ It is therefore essential that interventions address these barriers and are informed with a health equity approach. Our findings suggest that peer coaching interventions could help address some of these barriers. Although previous research has identified who participates in diabetes interventions, ${ }^{49-51}$ our findings add to the literature by exploring correlates of engagement in a peer coaching intervention.
Among veterans who were invited to participate in this intervention, patients who agreed to enroll had higher $\mathrm{HbA}_{1 \mathrm{c}}$ values and poorer self-reported self-management on average. These findings suggest that those most at risk for diabetes complications were more likely to enroll. Also, there were higher rates of enrollment among Black men. Although further exploration is needed to understand the factors contributing to higher enrollment rates, it is possible that the shared experience and identity of being veterans increased trust $^{52}$ in this health care offering, thus influencing enrollment. Given that perceived health care discrimination has been associated with higher $\mathrm{HbA}_{1 \mathrm{c}}$ levels for Black men (but not Black women), ${ }^{53}$ it is compelling that Black men and those with higher $\mathrm{HbA}_{1 \mathrm{c}}$ values were more likely to enroll in this intervention.

The higher rate of enrollment among patients with more formal education is consistent with findings of other studies and suggests the need for strategies to more effectively reach out to patients with less formal education. ${ }^{54}$ Patients who reported more difficulty feeling close to other people were also less likely to agree to enroll, which reinforces the need for different types of programs that meet a range of preferences for interacting with others and the need to understand contributing factors of those preferences.

Once patients agreed to enroll, no baseline patient characteristics were more associated than others with engaging in the program. The only variable associated with engagement was how highly participants rated their coach on a well-validated autonomy supportiveness scale at the completion of the 6-month intervention. The qualitative interviews with engaged patients also yielded a salient theme about the importance of autonomy-supportive communication from one's assigned coach. In previous peer support studies, participants who reported higher levels of autonomy support from their coach achieved better clinical outcomes than those reporting lower levels. ${ }^{55}$ As such, this investigation supports the importance of training and assessing coach fidelity in being noncontrolling and nonjudgmental, in avoiding unsolicited advice, and in not being overly directive in their interactions with peers. 
Table 4. Main Themes and Illustrative Quotes From Interviews With 14 Participants Who Engaged in the Peer Coaching Intervention

Common ground and shared experiences with coach (mentioned by 11 participants)

"We had a little bit more in common... He (coach) was a heavy set guy and lost weight, and he was telling me about his experiences with diabetes and what he was going through. And it was similar to mine-what I was going through. And it was a good vibe."

"We had a lot of things in common. For one, I like my crafts. I'm steady at it. We naturally discussed sports."

"Veteran conversations are very different, and after you're out of the service, you don't get to talk and hang around a lot of veterans. It was nice to talk to someone who has been to Taiwan, Hawaii, Germany, etc... Veteran talk."

"We talked about some things men don't usually talk about with each other-erectile dysfunction as a complication of diabetes. Guy talk is sometimes sterile, but [we] just broke it down... 2 guys with similar experiences, bouncing things off each other and being genuine with the answers, which were not the type that you would get from a stranger."

"He [coach] was telling me some of the things he had to go through and some of the things changed his life. I was like 'Wow, I went through the same stuff.' I would tell him about my feet pain... we would just [be] exchanging conversations and so forth. And I think that's when we really connected."

Encouraging, supportive, authentic stance from coach (mentioned by 10 participants)

"Yeah, I expected it to be more like a football coach, encourage you, egging you on all the time. Actually, it was a perfect relationship. He didn't push too hard, which I would have withdrew more. He came on at the right setting; he wasn't too pushy or not pushy enough."

"With him, I could keep it real. I could tell him I didn't do this or that. He didn't judge me. He would encourage me."

"I remember him asking 'How are you doing with your goals?' Then he would identify one or two that we made. Then he would ask me what actions could I take to get there. He didn't say, 'Aw you dummy!' He was positive and really showed that he wanted to help me take those steps to get to my goals."

"The encouragement. There were times he was willing to listen as much as he talked, and that was very helpful. You have to be willing to hear what other people say instead of just throwing your opinions at them."

\section{Accountability and consistency from coach (mentioned by 9 participants)}

"Having someone that was holding me accountable made me more serious about what I needed to do."

"...just having someone to check/monitor you on how you're doing. It kind of keeps you on your toes because you know you're going to hear from them."

"Because I would come close to the weekend when I would expect his call, I would think about it [diabetes] a little more and work on my goals a little bit better."

"He held me accountable to what I said I would do. Versus when I go to the doctor, they just generally ask what you are doing. With him, I was held accountable. I knew I would talk to him every week so I had to do what I said I would do."

Helpful tips and self-management information from coach (mentioned by $\mathbf{8}$ participants)

"He called me and we conversed... he gave me hints on how to eat proper, watching what I ate."

"Me and the coach talked quite a bit about exercise, being active, how that helps you feel better, how that helps the insulin absorb better. We had quite a few conversations about being more active was a definite benefit."

"I felt like he was really going to be able to help me. He told me about things that I didn't know about diabetes. [He] told me about some nutritional things, like my protein intake was important. He also gave me a lot of exercise tips."

"He (coach) was telling me the importance of about what you can gauge how you're doing, how well the medication is doing."

Intentional focus on improving self-management behaviors (mentioned by 8 participants)

"Changing my eating habits and exercising. Even watching the things I drink, just drinking more water. Basically just changing my lifestyle and remember who I was doing this for, which was myself. Just changing my thinking. Being more positive. It wasn't just about the diabetes. It was more about my overall health."

"Before, I wasn't taking my medicine like I should and that was a big problem. Now, every morning, boom, before I walk out the door I make sure I got my medicine" "[I] became more conscious of what I ate, started looking at labels more, cut out some foods, and watching my sugar intakes."

"I was a good vet for [this] because I was all in. I can't wait for [coach] to call me, because it's working."
Peer support interventions to date have not evaluated either racial nor sex differences in the importance of autonomy-supportive communication. It could be argued, however, that this communication style is especially relevant for interventions that target Black men due to existing disparities in patientcentered communication, which has been shown to promote health care engagement and outcomes. ${ }^{56,57}$ Similar to autonomy-supportive communication, patient-centered communication strategies promote shared understanding, decision making, and power while working to understand people's unique perspectives and meet emotional and informational needs.$^{58}$ Existing disparities have a negative impact on Black men because they contribute to medical mistrust and delay preventative care, demonstrating the importance of incorporating this communication style into interventions for Black men. ${ }^{59,60}$

The qualitative interviews yielded themes related to the importance of peer coach consistency, accountability, and sharing information on resources and self-management strategies, which suggests the need to screen for these characteristics when recruiting peer coaches. Multiple studies have discussed the relationship between accountability and behavior. ${ }^{61-63}$ Consistent peer coaching provides accountability, which patients in this study reported motivated their behavior changes. Also, coaches were perceived as trusted sources of diabetes self-management education because they themselves had struggled with their self-management but had succeeded in making improvements. These findings further support the importance of training peer coaches in available community and health system resources and appropriate ways to share self-management strategies without coaches operating outside of the scope of peer support. 
The need remains for extensive research on additional strategies to best design peer support and other health promotion programs that align with Black men's cultural and sex values. Incorporating dimensions of masculinity (ie, sex norms, roles, sex role conflict, and perceptions of masculinity) and race centrality into future investigations could yield insight into how those factors shape diabetes management for Black men. ${ }^{64}$ Using community-based participatory strategies to ensure that Black men are actively engaged in designing and providing feedback on intervention approaches could also help provide further insight. ${ }^{65}$ Future research should additionally examine whether race, sex, age, veteran status, or other shared characteristics between participant and peer coach further enhance patient experience, outcomes, or both in peer support interventions. Finally, it is important to continue to investigate the characteristics of effective peer coaches, to design measures that assess factors contributing to effective peer pairings, and to evaluate optimal duration of these interventions.

Our findings need to be interpreted in the face of several limitations. First, only $40 \%$ of those who declined enrollment agreed to answer a brief survey, which may have led to underrepresentation of specific groups of patients and their opinions. There are also limits to the generalizability of these findings because this study was conducted in a single health system with predominantly male veteran participants, and the mean age of participants was 66.9 years, so findings may not apply broadly to other sites, settings, or populations.

To read or post commentaries in response to this article, go to https://www.AnnFamMed.org/content/19/6/532/tab-e-letters.

Key words: diabetes; peer support; health coaching; T2DM; chronic care: patient self-management support; engagement; Black men; healthcare disparities; health services; practice-based research

Submitted July 10, 2020; submitted, revised, May 6, 2021; accepted June 3, 2021.

Funding support: This research was supported by grant 12-412 from the VA HSRED and by grant P30DK092926 (MCDTR) from the National Institute of Diabetes and Digestive and Kidney Diseases.

Clinical Trial Registration (https://clinicaltrials.gov/): NCT01855399.

Supplemental materials: Available at https://www.AnnFamMed. org/lookup/suppl/doi:10.1370/afm.2742/-/DC1.

\section{References}

1. Idris I, Hampton J, Moncrieff F, Whitman M. Effectiveness of a digital lifestyle change program in obese and type 2 diabetes populations: service evaluation of real-world data. JMIR Diabetes. 2020; 5(1):e15189.

2. Zheng Y, Ley SH, Hu FB. Global aetiology and epidemiology of type 2 diabetes mellitus and its complications. Nat Rev Endocrinol. 2018;14(2):88-98.

3. Centers for Disease Control and Prevention. National Diabetes Statistics Report 2020. Centers for Disease Control and Prevention; 2020.
4. Liburd LC, Namageyo-Funa A, Jack L Jr. Understanding "masculinity" and the challenges of managing type-2 diabetes among African-American men. J Natl Med Assoc. 2007;99(5):550-552, 554-558.

5. Jack $L$ Jr. A candid conversation about men, sexual health, and diabetes. Diabetes Educ. 2005;31(6):810-817.

6. Hawkins J, Watkins DC, Kieffer E, Spencer M, Espitia N, Anderson $M$. Psychosocial factors that influence health care use and selfmanagement for African American and Latino men with type 2 diabetes: an exploratory study. J Men's Stud. 2015;23(2):161-176.

7. Centers for Disease Control and Prevention. Health Disparities Experienced by Black or African Americans-United States. Centers for Disease Control and Prevention; 2005.

8. Heisler M, Smith DM, Hayward RA, Krein SL, Kerr EA. Racial disparities in diabetes care processes, outcomes, and treatment intensity. Med Care. 2003;41(11):1221-1232.

9. Peek ME. Gender differences in diabetes-related lower extremity amputations. Clin Orthop Relat Res. 2011;469(7):1951-1955.

10. Shen $Y$, Shi L, Nauman $E$, et al. Race and sex differences in rates of diabetic complications. J Diabetes. 2019;11(6):449-456.

11. Cooper LA, Roter DL, Johnson RL, Ford DE, Steinwachs DM, Powe NR. Patient-centered communication, ratings of care, and concordance of patient and physician race. Ann Intern Med. 2003;139(11):907-915.

12. Frosch DL, May SG, Rendle KAS, Tietbohl C, Elwyn G. Authoritarian physicians and patients' fear of being labeled 'difficult' among key obstacles to shared decision making. Health Aff (Millwood). 2012; 31(5):1030-1038.

13. Peek ME, Quinn MT, Gorawara-Bhat R, Odoms-Young A, Wilson SC, Chin $\mathrm{MH}$. How is shared decision-making defined among AfricanAmericans with diabetes? Patient Educ Couns. 2008;72(3):450-458.

14. Hunt KJ, Davis M, Pearce J, et al. Geographic and racial/ethnic variation in glycemic control and treatment in a national sample of veterans with diabetes. Diabetes Care. 2020;43(10):2460-2468.

15. Brown EA, Ward RC, Weeda E, Taber DJ, Axon RN, Gebregziabher M. Racial-geographic disparity in lipid management in veterans with type 2 diabetes: a 10-year retrospective cohort study. Health Equity. 2019;3(1):472-479.

16. Alexopoulos A-S, Jackson GL, Edelman D, et al. Clinical factors associated with persistently poor diabetes control in the Veterans Health Administration: a nationwide cohort study. PLoS One. 2019;14(3): e0214679.

17. Kurtz SMS. Adherence to diabetes regimens: empirical status and clinical applications. Diabetes Educ. 1990;16(1):50-59.

18. Glasgow RE, McCaul KD, Schafer LC. Self-care behaviors and glycemic control in type I diabetes. J Chronic Dis. 1987;40(5):399-412.

19. Mayberry LS, Bergner EM, Chakkalakal RJ, Elasy TA, Osborn CY. Self-care disparities among adults with type 2 diabetes in the USA. Curr Diab Rep. 2016;16(11):113.

20. Hawkins JM. Type 2 diabetes self-management in non-Hispanic Black men: a current state of the literature. Curr Diab Rep. 2019;19(3):10.

21. Goldstein LA, Mehling WE, Metzler TJ, et al. Veterans group exercise: a randomized pilot trial of an integrative exercise program for veterans with posttraumatic stress. J Affect Disord. 2018;227:345-352.

22. Moin T, Damschroder LJ, AuYoung M, et al. Results from a trial of an online diabetes prevention program intervention. Am J Prev Med. 2018;55(5):583-591.

23. Piette JD, Resnicow K, Choi H, Heisler M. A diabetes peer support intervention that improved glycemic control: mediators and moderators of intervention effectiveness. Chronic Illn. 2013;9(4):258-267.

24. Fisher EB, Boothroyd RI, Coufal MM, et al. Peer support for selfmanagement of diabetes improved outcomes in international settings. Health Aff (Millwood). 2012;31(1):130-139.

25. Gallant MP. The influence of social support on chronic illness selfmanagement: a review and directions for research. Health Educ Behav. 2003;30(2):170-195. 
26. Heisler M, Vijan S, Makki F, Piette JD. Diabetes control with reciprocal peer support versus nurse care management: a randomized trial. Ann Intern Med. 2010;153(8):507-515.

27. Thom DH, Ghorob A, Hessler D, De Vore D, Chen E, Bodenheimer TA. Impact of peer health coaching on glycemic control in lowincome patients with diabetes: a randomized controlled trial. Ann Fam Med. 2013;11(2):137-144.

28. Ghorob A, Vivas MM, De Vore D, et al. The effectiveness of peer health coaching in improving glycemic control among low-income patients with diabetes: protocol for a randomized controlled trial. BMC Public Health. 2011;11:208.

29. Litchman ML, Oser TK, Hodgson L, et al. In-person and technologymediated peer support in diabetes care: a systematic review of reviews and gap analysis. Diabetes Educ. 2020;46(3):230-241.

30. Long JA, Jahnle EC, Richardson DM, Loewenstein G, Volpp KG. Peer mentoring and financial incentives to improve glucose control in African American veterans: a randomized trial. Ann Intern Med. 2012;156(6):416-424.

31. Mase $R$, Halasyamani $L$, Choi $H$, Heisler M. Who signs up for and engages in a peer support heart failure self-management intervention. J Cardiovasc Nurs. 2015;30(4)(Suppl 1):S35-S43.

32. Fisher EB, Boothroyd RI, Elstad EA, et al. Peer support of complex health behaviors in prevention and disease management with special reference to diabetes: systematic reviews. Clin Diabetes Endocrinol. 2017;3(1):4.

33. Patil SJ, Ruppar T, Koopman RJ, et al. Peer support interventions for adults with diabetes: a meta-analysis of hemoglobin $A_{1 c}$ outcomes. Ann Fam Med. 2016;14(6):540-551.

34. Heisler M, Choi H, Mase R, Long JA, Reeves PJ. Effectiveness of technologically enhanced peer support in improving glycemic management among predominantly African American, low-income adults with diabetes. Diabetes Educ. 2019;45(3):260-271.

35. Heisler M, Mase R, Brown B, Wilson S, Reeves PJ. Study protocol: the Technology-Enhanced Coaching (TEC) program to improve diabetes outcomes - a randomized controlled trial. Contemp Clin Trials. 2017;55:24-33.

36. Gill T, Taylor A, Broderick D, Avery J, Dal Grande E. Self reported overall health status: implications for intervention strategies. Australas Med J. 2008;1(8):44-57.

37. Barrera M Jr, Glasgow RE, McKay HG, Boles SM, Feil EG. Do Internet-based support interventions change perceptions of social support?: an experimental trial of approaches for supporting diabetes self-management. Am J Community Psychol. 2002;30(5):637-654.

38. Ciechanowski P, Russo J, Katon W, et al. Influence of patient attachment style on self-care and outcomes in diabetes. Psychosom Med. 2004;66(5):720-728.

39. Tang TS, Brown MB, Funnell MM, Anderson RM. Social support, quality of life, and self-care behaviors among African Americans with type 2 diabetes. Diabetes Educ. 2008;34(2):266-276.

40. Morisky DE, Ang A, Krousel-Wood M, Ward HJ. Predictive validity of a medication adherence measure in an outpatient setting. $J$ Clin Hypertens (Greenwich). 2008;10(5):348-354.

41. Fisher L, Glasgow RE, Mullan JT, Skaff MM, Polonsky WH. Development of a brief diabetes distress screening instrument. Ann Fam Med. 2008;6(3):246-252.

42. O'Connor AM. Validation of a decisional conflict scale. Med Decis Making. 1995;15(1):25-30.

43. Sebire SJ, Banfield K, Jago R, et al. A process evaluation of the PLAN-A intervention (Peer-Led physical Activity iNtervention for Adolescent girls). BMC Public Health. 2019;19(1):1203.

44. Taylor RW, Williams SM, Dawson AM, Taylor BJ, Meredith-Jones K, Brown D. What factors influence uptake into family-based obesity treatment after weight screening? J Pediatrics. 2013;163(6): 1657.e1-1662.e1.

45. Gensichen J, Von Korff M, Rutter CM, et al. Physician support for diabetes patients and clinical outcomes. BMC Public Health. 2009; 9:367.
46. Corbin JM. Strauss AL. Basics of Qualitative Research: Techniques and Procedures for Developing Grounded Theory. 4th ed. Sage Publications; 2015.

47. Gamble VN. Under the shadow of Tuskegee: African Americans and health care. Am J Public Health. 1997;87(11):1773-1778.

48. Shavers VL, Fagan $P$, Jones $D$, et al. The state of research on racial/ ethnic discrimination in the receipt of health care. Am J Public Health. 2012;102(5):953-966.

49. Hawkins J, Kieffer EC, Sinco B, Spencer M, Anderson M, Rosland A-M. Does gender influence participation? Predictors of participation in a community health worker diabetes management intervention with African American and Latino adults. Diabetes Educ. 2013; 39(5):647-654.

50. James DC, Harville C II, Sears C, Efunbumi O, Bondoc I. Participation of African Americans in e-health and m-health studies: a systematic review. Telemed J E Health. 2017;23(5):351-364.

51. Sherman LD, Hawkins JM, Bonner T. An analysis of the recruitment and participation of African American men in type 2 diabetes selfmanagement research: a review of the published literature. Soc Work Public Health. 2017;32(1):38-48.

52. Black KJ, Britt TW, Zinzow HM, Pury CLS, Cheung JH. The role of social support in treatment seeking among soldiers. Occup Health Sci. 2019;3(10):337-361

53. Assari S, Lee DB, Nicklett EJ, Moghani Lankarani M, Piette JD, Aikens JE. Racial discrimination in health care is associated with worse glycemic control among Black men but not Black women with type 2 diabetes. Front Public Health. 2017;5:235.

54. Bonevski B, Randell M, Paul C, et al. Reaching the hard-to-reach: a systematic review of strategies for improving health and medical research with socially disadvantaged groups. BMC Med Res Methodol. 2014;14(1):42.

55. Leahey TM, Wing RR. A randomized controlled pilot study testing three types of health coaches for obesity treatment: professional, peer, and mentor. Obesity (Silver Spring). 2013;21(5):928-934.

56. Mitchell JA, Perry R. Disparities in patient-centered communication for Black and Latino men in the U.S.: cross-sectional results from the 2010 health and retirement study. PLoS One. 2020;15(9):e0238356.

57. DeVoe JE, Wallace LS, Fryer GE Jr. Measuring patients' perceptions of communication with healthcare providers: do differences in demographic and socioeconomic characteristics matter? Health Expect. 2009;12(1):70-80.

58. King A, Hoppe RB. "Best practice" for patient-centered communication: a narrative review. J Grad Med Educ. 2013;5(3):385-393.

59. Powell W, Adams LB, Cole-Lewis Y, Agyemang A, Upton RD. Masculinity and race-related factors as barriers to health help-seeking among African American men. Behav Med. 2016;42(3):150-163.

60. Hammond WP, Matthews D, Mohottige D, Agyemang A, CorbieSmith G. Masculinity, medical mistrust, and preventive health services delays among community-dwelling African-American men. J Gen Intern Med. 2010;25(12):1300-1308.

61. Lerner JS, Tetlock PE. Accounting for the effects of accountability. Psychol Bull. 1999;125(2):255-275.

62. Mohr DC, Cuijpers P, Lehman K. Supportive accountability: a model for providing human support to enhance adherence to eHealth interventions. J Med Internet Res. 2011;13(1):e30.

63. Watson A, Bickmore T, Cange A, Kulshreshtha A, Kvedar J. An Internet-based virtual coach to promote physical activity adherence in overweight adults: randomized controlled trial. J Med Internet Res. 2012;14(1):e1.

64. Jack L Jr, Toston T, Jack NH, Sims M. A gender-centered ecological framework targeting Black men living with diabetes: integrating a "masculinity" perspective in diabetes management and education research. Am J Mens Health. 2010;4(1):7-15.

65. Unertl KM, Schaefbauer CL, Campbell TR, et al. Integrating community-based participatory research and informatics approaches to improve the engagement and health of underserved populations. J Am Med Inform Assoc. 2016;23(1):60-73. 